\title{
Propagation of bichromatic-bidirectional waves
}

\author{
Propagação de ondas bicromáticas e bidirecionais
}

\author{
Mario Grüne de Souza e Silva ${ }^{1}$, Paulo Cesar Colonna Rosman ${ }^{1}$ and Claudio Freitas Neves ${ }^{1}$ \\ ${ }^{1}$ Universidade Federal do Rio de Janeiro, Rio de Janeiro, RJ, Brasil \\ E-mails: mariosilva@poli.ufrj.br (MGSS),pccrosman@gmail.com (PCCR), neves@oceanica.ufrj.br (CFN)
}

Received: June 08, 2018 - Revised: September 20, 2018 - Accepted: November 05, 2018

\begin{abstract}
This study aims to investigate the transformations experienced by the mean water level and radiation stress tensor during the propagation of Bichromatic-Bidirectional (Bi-Bi) waves on a slope of 1:22 and water depth varying from $55 \mathrm{~cm}$ to $26 \mathrm{~cm}$, simulating laboratory conditions. A computer program written in Python was used to compute those quantities at different combinations of wave angles and periods. The setup and setdown of the mean water level are strongly dependent on the combination of periods and direction of the primary waves, as they propagate along the slope, modifying the bound infragravity wave. Mohr's circles for the radiation stress tensor showed significant changes of diameter and center at different points along the basin. The radiation stress components for the $\mathrm{Bi}-\mathrm{Bi}$ waves are the sum of the stresses associated with each primary wave and a nonlinear term which results from the interference between primary waves. Disregarding these nonlinear terms may significantly affect the nearshore hydrodynamics prediction.
\end{abstract}

Keywords: Bimodal seas; Infragravity waves; Radiation stress; Nonlinear wave-wave interaction.

\section{RESUMO}

Este trabalho tem por objetivo investigar as transformações sobre o nível médio da água e o tensor de tensão de radiação durante a propagação de ondas Bicromáticas e Bidirecionais (Bi-Bi) em um talude 1:22 e profundidades variando de $55 \mathrm{~cm}$ a $26 \mathrm{~cm}$, simulando uma bacia de ondas em laboratório. Um modelo matemático escrito em Python foi utilizado para o cálculo daquelas grandezas para diferentes combinações de ângulos e períodos de ondas. A sobre-elevação e o rebaixamento do nível médio da água são fortemente dependentes da combinação de períodos e direções escolhidos para as ondas primárias, dado que elas refratam ao longo do talude, modificando assim a onda de infragravidade aprisionada. Os círculos de Mohr para o tensor de tensões de radiação mostraram mudanças significativas no diâmetro e no posicionamento do centro em diferentes pontos ao longo da bacia. As componentes da tensão de radiação para as ondas Bi-Bi são a soma das tensões associadas a cada onda primária e um termo não linear que resulta da interferência entre as ondas primárias. Ao se desconsiderar estes termos não-lineares pode-se causar consequências significativas sobre previsão da circulação hidrodinâmica.

Palavras-chave: Mar bimodal; Ondas de infragravidade; Tensão de radiação; Interação não-linear onda-onda. 


\section{INTRODUCTION}

Infragravity waves are long surface waves with frequencies ranging from $0.004 \mathrm{~Hz}$ to $0.04 \mathrm{~Hz}$, and amplitudes of $\mathrm{O}\left(10^{0}-10^{1} \mathrm{~cm}\right)$. Their wavelengths can be much longer than those typical of free wind-generated waves, $\mathrm{O}\left(10^{2}-10^{3} \mathrm{~m}\right)$, making them difficult to be identified in the sea. The first observations of these low-frequency oscillations were made by Munk (1949) and Tucker (1950). The phenomenon was named "surf beat" and associated with the envelope of wave groups that caused a variable mass transport inside the group.

According to Bertin et al. (2018), infragravity waves are now widely accepted as responsible for significant impacts on the hydrodynamics and morphodynamics of coastal areas like sandy beaches, tidal inlets, coral reefs and harbors. These long period oscillations can drive rip currents (DALRYMPLE et al., 2011), can propagate into aquifers on sandy coasts and cause underground water fluxes through barrier islands, between sea and lagoons (GENG; BOUFADEL, 2015; LI; BARRY, 2000; LONGUET-HIGGINS, 1983), can intensify wave run-up and overtopping over dunes, structures and fringing coral reefs (CHERITON; STORLAZZI; ROSENBERGER, 2016) and can eventually dominate the net sediment transport in the surf zone (AAGAARD; GREENWOOD, 2008). Janssen (2003) reported that the slow modulation of the infragravity waves can cause resonance inside harbors, affecting the moored ship behavior and the design wave characteristics for port structures. According to the author, the forcing of infragravity waves may even "be normative to their design". Infragravity waves have been associated with microseisms (LONGUET-HIGGINS, 1950), can cause vibrations in coastal cliffs, leading to their instability and erosion (YOUNG et al., 2011), and are related to seismic waves in the solid Earth, a phenomenon known as "the hum" (ARDHUIN; GUALTIERI; STUTZMANN, 2015).

The first mathematical explanation for the generation of infragravity waves came with the pioneering work of Longuet-Higgins and Stewart (1964) where the concept of radiation stress for ocean waves was defined as the excess of momentum flux due to the presence of the waves. According to the authors, the radiation stress is proportional to the square of the wave height and has tensor like nature. Equations (1) to (3) show the normal and shear components of the stress tensor $(\mathrm{S})$, where $\mathrm{E}$ is the wave energy per unit area $\left(\mathrm{J} / \mathrm{m}^{2}\right) ; \mathrm{n}$ is the ratio of group velocity to wave celerity; and $\theta$ is the wave angle of propagation relative to the coordinate system $\mathrm{x}-\mathrm{y}$.

$$
\begin{aligned}
& S_{x x}=E\left[n\left(\cos ^{2} \theta+1\right)-\frac{1}{2}\right] \\
& S_{y y}=E\left[n\left(\sin ^{2} \theta+1\right)-\frac{1}{2}\right] \\
& S_{x y}=\frac{E}{2} n \sin 2 \theta
\end{aligned}
$$

Therefore, inside a wave group, where a slow periodical change of the individual (short period) wave heights exists, there will also be a variation of the radiation stress, which will be compensated by the gradient of the mean water level from the regions of higher to lower wave heights, known as wave setup and setdown. Figure 1 shows a sketch of a wave group formed by two collinear short period waves and the associated infragravity wave, which has a phase shift of $180^{\circ}$ relative to the group envelope. If the primary waves have periods $\mathrm{T}_{\mathrm{a}}$ and $\mathrm{T}_{\mathrm{b}}$, the infragravity wave will have period $\mathrm{T}_{\mathrm{a}} \mathrm{T}_{\mathrm{b}} /\left|\mathrm{T}_{\mathrm{a}}-\mathrm{T}_{\mathrm{b}}\right|$.

According to the classification of Zhang and Chen (1999), this long period wave is a 'strong' interaction characteristic between primary waves, which appears immediately after the start of the propagation of free waves. It is also a "bound wave", as its existence strictly depends on the existence of the primary waves and it propagates with the group celerity and not according to the dispersion relation (JANSSEN, 2003).

Although the concept of radiation stresses has been known for decades, little attention has been given to the problem of the stress field associated with two non-collinear waves. Hsu et al. (2006) investigated the influence of the directionality of the incoming wave on the radiation stresses and in the wave setup and setdown. Shi and Kirby (2008) and Hsu and Lan (2009) later made some corrections to the original work, and verified that oblique waves were not capable of driving nearshore circulations outside the surf zone. However, none of them studied the effects of two different wave systems reaching the coast at the same time.

The present article extends those previous studies by analyzing the radiation stress field associated to Bichromatic-Bidirectional waves, from now on referred to as $\mathrm{Bi}-\mathrm{Bi}$ waves. This condition should be interpreted as a simplified view for bimodal seas, a state very often found in Nature (RAPIZO et al., 2015), and more specifically in the southeast and northeast coast of Brazil (MELO et al., 1995; PARENTE et al., 2015). Although occurrences of infragravity waves associated to these sea conditions are known, their effects on littoral processes and nearshore hydrodynamics are still research topics.

\section{MATERIAL AND METHODS}

In this section, wave (geometrical) refraction will be reviewed, and the analytical second order equations for the mean water level and radiation stresses are derived. Following Dean and Dalrymple (1991), mean values for second order properties are obtained from depth integrated or time averaged equations, based solely on first order solution substituted into nonlinear

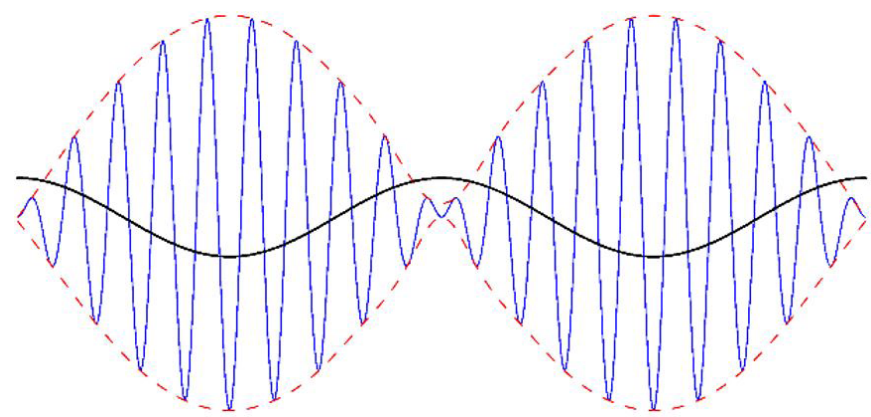

Figure 1. Wave group composed by two collinear bichromatic waves and the generated infragravity wave. 
terms of the expressions of momentum flux and dynamic free surface boundary condition.

\section{Wave refraction}

In geometric optics, refraction is defined as a change in celerity as a wave propagates across a variable medium, resulting in a change in the direction of propagation of the light ray. A direct analogy applies between light rays and water waves, if the refraction index, which is defined as the ratio between the local speed of light and the speed in vacuum, is defined as the ratio between the local celerity and deep-water celerity. The analogy however does not extend to the physics of refraction of both types of waves. First, the speed of light in vacuum is a universal constant, whereas the wave celerity in deep water varies with the wave frequency (or period or length) because water waves are dispersive. Second, the intensity of the water wave (height) changes along the refraction path, unlike the light waves.

At this point, it is important to address two common misconceptions about the refraction of water waves. The bathymetry will be considered to have straight depth contours, all parallel to the shore. First of all, as waves approach the shore, the crests never become parallel to the isobaths. Applying Snell's Law (4),

$\frac{c_{1}}{c_{2}}=\frac{\sin \theta_{1}}{\sin \theta_{2}}$

where $\theta_{i}$ is the angle of the crest with the depth contour at depth $h_{i}$ or the angle between the wave number and the normal to the depth contour. The angle $\theta_{i}$ can only be zero (normal incidence) if the wave celerity at depth $h_{i}$ is zero, consequently if the depth itself is null.

Second, as a wave propagates towards shallower water, its height actually decreases by approximately $10 \%$ or even more, depending on the angle of incidence. Figure 2 shows an example of the ratio between local wave height $(\mathrm{H})$ to deep water wave height $\left(\mathrm{H}_{0}\right)$ for different values of incidence. For a deep water angle of incidence of $50^{\circ}$, for instance, the wave height returns to be the same at relative water depth $(\mathrm{h} / \mathrm{L})$ equal to 0.0578 , very close to shallow water limit.

If one considers the simultaneous refraction of two wave trains (say, wave 'a' and wave 'b') across the parallel contour bathymetry,

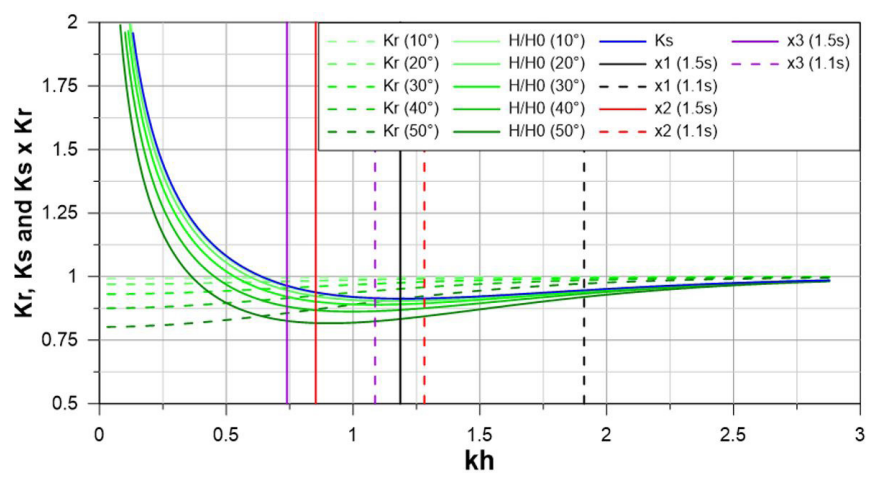

Figure 2. Shoaling and refraction coefficient. the patterns of interaction will change, as the orientations of the crests of each wave will evolve. In other words, the individual wave rays will undergo refraction differently from each other. At a given point with known depth $\mathrm{h}$, for wave ' $a$ ' it will correspond a relative water depth $h / L_{a}$, while for wave ' $b$ ' it will correspond a relative water depth $h / \mathrm{L}_{b}$. This means also that each primary wave would be undergoing different processes (for instance, changes in wave height or second order effects) at the location of interaction. The vertical lines in Figure 2 correspond to three points $\left(\mathrm{x}_{1}, \mathrm{x}_{2}\right.$ and $\left.\mathrm{x}_{3}\right)$ with different depths (say, $\mathrm{h}_{1}, \mathrm{~h}_{2}$ and $\left.\mathrm{h}_{3}\right)$; for each point, the relative depth $(\mathrm{h} / \mathrm{L})$ for the $1.1 \mathrm{~s}$ wave (dashed line) will differ from those for the $1.5 \mathrm{~s}$ wave (solid line).

\section{Mean water level}

Using second order Stokes theory, Dalrymple (1975) studied the interaction between two waves with the same frequency but different directions of propagation. This condition may happen as waves are reflected by a structure or a natural morphological feature. It was shown that these monochromatic-bidirectional wave trains generate static longshore undulations of the mean water level, which may be one of the possible mechanisms for rip currents formation and an explanation for the equal spacing between them (INMAN; TAIT; NORDSTROM, 1971). In the surf zone, these spatial oscillations modulate the wave height and wave-induced circulation along the coast, which is usually attributed to edge waves or irregular bottom topography (DALRYMPLE et al., 2011; XIE, 2012). Dalrymple (1975) analytically derived the mean water level under the effects of monochromatic-bidirectional wave groups by time-averaging the Bernoulli equation. The following expression results:

$$
\bar{\eta}=-\frac{k}{8 \sinh (2 k h)}\left\{\left\{\left[\begin{array}{l}
H_{a}^{2}+H_{b}^{2}+4 H_{a} H_{b} \sinh ^{2}(k h) \times \\
\left.\left\{1-\frac{\cos (\Delta \theta)}{\tanh ^{2}(k h)}\right] \cos (\Delta \mathbf{k} \cdot \mathbf{x})\right\}
\end{array}\right\}\right.\right.
$$

where $\mathbf{x}=(\mathrm{x}, \mathrm{y})$ where $\mathrm{x}$ is the cross-shore coordinate positive in the landward direction $(\mathrm{m})$ and $\mathrm{y}$ is the longshore coordinate positive to the right of an observer looking seaward (m); $\mathrm{h}=$ local $\operatorname{depth}(\mathrm{m}) ; \mathrm{H}=$ wave height $(\mathrm{m}) ; \mathbf{\Delta} \mathbf{k}=\left(\mathbf{k}_{\mathbf{a}}-\mathbf{k}_{\mathrm{b}}\right)=$ difference wave number vector $\left(\mathrm{rad} \cdot \mathrm{m}^{-1}\right) ; \Delta \theta=\left(\theta_{\mathrm{a}}-\theta_{\mathrm{b}}\right)=$ difference between the two incident wave angles (radian); and the subscripts ' $a$ ' and 'b' correspond to each wave. It should be observed that Equation (5) describes a stationary undulation that would be present along the coastline during the occurrence of such a sea state. Dalrymple and Lanan (1976) conducted physical model tests to verify the existence of this stationary long wave and associated nearshore circulations.

However, if two waves have different directions and different frequencies (Bi-Bi waves) other phenomena occur and time-averaging the Bernoulli equation is not suitable anymore. Using the Sharma and Dean (1981) equation for the instantaneous free surface elevation, the following expression for the mean water level is obtained: 


$$
\begin{gathered}
\bar{\eta}=-\frac{H_{a}^{2} k_{a}}{8 \sinh \left(2 k_{a} h\right)}-\frac{H_{b}^{2} k_{b}}{8 \sinh \left(2 k_{b} h\right)}+\frac{H_{a} H_{b}}{8 g} \times \\
\left\{\sigma_{a}^{2}+\sigma_{b}^{2}-\frac{\sigma_{a} \sigma_{b} \cos (\Delta \theta)}{\tanh \left(k_{a} h\right) \tanh \left(k_{b} h\right)}+\sigma_{a} \sigma_{b}\right\} \times \\
\frac{\cos \left(\phi_{a}+\phi_{b}\right)}{+H_{a} H_{b}} 8 \times \\
\frac{\left\{\sigma_{a}^{2}+\sigma_{b}^{2}-\frac{\sigma_{a} \sigma_{b} \cos (\Delta \theta)}{\tanh \left(k_{a} h\right) \tanh \left(k_{b} h\right)}-\sigma_{a} \sigma_{b}\right\} \times}{\cos \left(\phi_{a}-\phi_{b}\right)}+\frac{1}{g}\left(\sigma_{a}+\sigma_{b}\right) \cosh \left(\left|\mathbf{k}_{\mathbf{a}}+\mathbf{k}_{\mathbf{b}}\right| h\right) \times \\
A_{a b}^{+} \overline{\cos \left(\phi_{a}+\phi_{b}\right)}+\frac{1}{g}\left(\sigma_{a}-\sigma_{b}\right) \times \\
\cosh \left(\left|\mathbf{k}_{\mathbf{a}}-\mathbf{k}_{\mathbf{b}}\right| h\right) A_{a b}^{-} \overline{\cos \left(\phi_{a}-\phi_{b}\right)}
\end{gathered}
$$

where $\mathrm{g}=$ acceleration of gravity $\left(\mathrm{m} / \mathrm{s}^{2}\right) ; \sigma=$ wave frequency $(\mathrm{Hz}) ; \phi=$ wave phase $(\phi=\mathbf{k} \cdot \mathbf{x}-\sigma t+\varepsilon) ; \varepsilon=$ initial wave phase; and $\mathrm{A}^{+}$ and $\mathrm{A}^{-}$are terms of additive and subtractive interaction between the primary waves, respectively, given by expressions (7) and (8).

Unlike the equation derived by Dalrymple (1975), Equation (6) has terms which vary in time. The terms that involve the addition of phases are known as additive interference. They will have higher frequency, although the wave length will depend on the angle between the primary wave number vectors. Note that in Equation (7) the sum of the wave vector numbers is involved, while in Equation (8), the wave vector numbers of the primary waves are subtracted.

If the two primary frequencies are close to each other, averaging over the main period will render the additive terms equal to zero. On the other hand, if the two frequencies are rather different, say $1.1 \mathrm{~s}$ and $1.5 \mathrm{~s}$, a short period term $\left(T_{+}=0.63 \mathrm{~s}\right)$ will appear. Figure 3 illustrates the influence of the angle difference between the two primary waves. For small angles, the additive interference has higher frequency and shorter length compared to the individual waves, whereas the subtractive interference will have lower frequency and longer wave length. If the angle difference is large, however, the additive interference may have longer wave length whereas the subtractive interference will have shorter wave length.

Observe that Equation (5) is retrieved from Equation (6) if: (i) monochromatic-bidirectional waves are considered; (ii) the time average of the additive interaction is neglected; (iii) the magnitudes of the wave number vectors are the same for waves with same

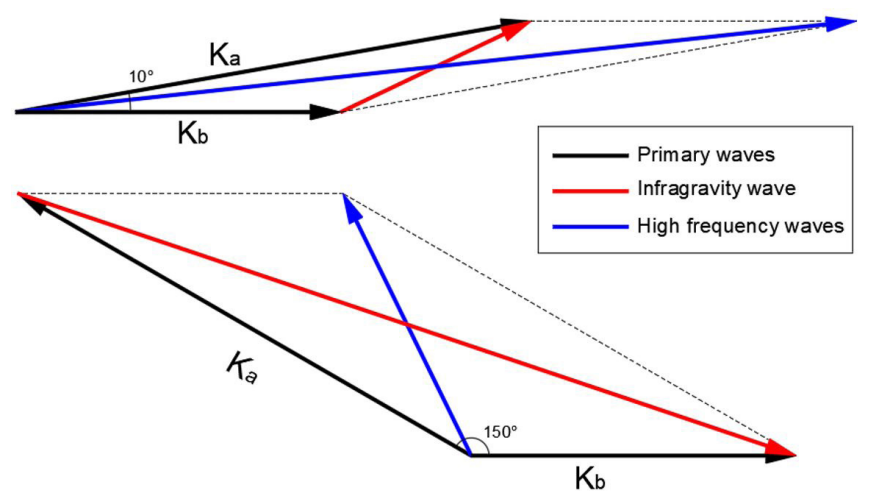

Figure 3. Wave number vectors of the primary waves and their additive (blue) and subtractive (red) second order interactions. period; and (iv) the phase of the subtractive interaction does not depend on the time when waves have the same period.

$$
\begin{aligned}
& \left.\begin{array}{c}
A_{a b}^{+}=-\frac{H_{a} H_{b}}{4} \times \\
\frac{g k_{a} \sigma_{a}}{\sinh \left(2 k_{a} h\right)}+\frac{g k_{b} \sigma_{b}}{\sinh \left(2 k_{b} h\right)}+ \\
\sigma_{a} \sigma_{b}\left(\sigma_{a}+\sigma_{b}\right)\left[\frac{\cos (\Delta \theta)}{\tanh \left(k_{a} h\right) \tanh \left(k_{b} h\right)}-1\right]
\end{array}\right\} \div \\
& \left\{\begin{array}{c}
g\left|\mathbf{k}_{\mathbf{a}}+\mathbf{k}_{\mathbf{b}}\right| \sinh \left(\left|\mathbf{k}_{\mathbf{a}}+\mathbf{k}_{\mathbf{b}}\right| h\right)- \\
\left(\sigma_{a}+\sigma_{b}\right)^{2} \cosh \left(\left|\mathbf{k}_{\mathbf{a}}+\mathbf{k}_{\mathbf{b}}\right| h\right)
\end{array}\right\} \\
& \begin{array}{c}
A_{a b}^{-}=-\frac{H_{a} H_{b}}{4} \times \\
\left\{\begin{array}{c}
\frac{g k_{a} \sigma_{a}}{\sinh \left(2 k_{a} h\right)}-\frac{g k_{b} \sigma_{b}}{\sinh \left(2 k_{b} h\right)}+ \\
\sigma_{a} \sigma_{b}\left(\sigma_{a}-\sigma_{b}\right)\left[\frac{\cos (\Delta \theta)}{\tanh \left(k_{a} h\right) \tanh \left(k_{b} h\right)}+1\right]
\end{array}\right\} \div \\
\left\{\begin{array}{c}
g\left|\mathbf{k}_{\mathbf{a}}-\mathbf{k}_{\mathbf{b}}\right| \sinh \left(\left|\mathbf{k}_{\mathbf{a}}-\mathbf{k}_{\mathbf{b}}\right| h\right)- \\
\left(\sigma_{a}-\sigma_{b}\right)^{2} \cosh \left(\left|\mathbf{k}_{\mathbf{a}}-\mathbf{k}_{\mathbf{b}}\right| h\right)
\end{array}\right\}
\end{array}
\end{aligned}
$$

Physically, the Bi-Bi wave causes a bound progressive long wave, which propagates in the direction of the vector which results from the subtraction of the two primary wave vectors (Figure 3). Similar to the stationary wave associated with a monochromatic-bidirectional sea state, one may infer that the infragravity wave produced by $\mathrm{Bi}-\mathrm{Bi}$ waves generates rip currents. However, this progressive bound wave would also be able to cause the longitudinal displacement of the rip currents, a phenomenon commonly seen in Nature (FOWLER; DALRYMPLE, 1990). Equation (6) reduces to the expressions for the wave set-down of progressive and standing waves if the angle differences are taken as $0^{\circ}$ or $180^{\circ}$, and the frequencies are the same.

\section{Radiation stresses}

The expressions of the radiation stresses for $\mathrm{Bi}$ - $\mathrm{Bi}$ waves are given by Equation (9), where $\mathrm{S}_{\mathrm{ij}}$ are the components of the radiation stress tensor $(\mathrm{N} / \mathrm{m})$; $\tilde{u}$ and $\tilde{\mathrm{v}}$ are components of the horizontal orbital velocities of waves ' $a$ ' and 'b' ( $\mathrm{m} / \mathrm{s})$, respectively; $\mathrm{p}$ is the pressure term $\left(\mathrm{N} / \mathrm{m}^{2}\right), \varrho$ is the density of the medium $\left(\mathrm{kg} / \mathrm{m}^{3}\right)$, $\delta$ is the Kronecker delta, the overbar means time averaging, and the subscripts $i$ and $j$ correspond to the Cartesian components $\mathrm{x}$ and $\mathrm{y}$, respectively. This equation differs from the simple linear superposition due to the presence of the interaction components $\left(\tilde{u}_{i} \tilde{v}_{j}\right.$ and $\left.\tilde{u}_{j} \tilde{v}_{i}\right)$ and by the mean water level itself, given by Equation (6).

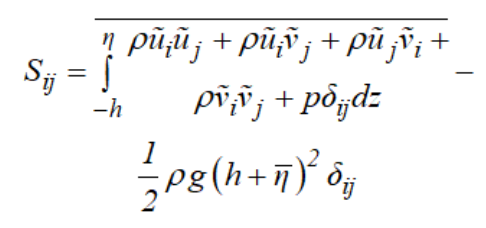

After some algebraic manipulation, the complete equations are derived for the terms of the radiation stress, which assume the general form shown in Equation (10). The complete equations are given in Appendix 1, and they have the general form: 
$S_{i j}=S_{i j a}+S_{i j b}+\psi^{ \pm} \overline{\cos \left(\phi_{a} \pm \phi_{b}\right)}$

where $\psi^{ \pm}$represents a nonlinear interaction function (additive or subtractive) that depends on the physical and geometrical properties of waves ' $a$ ' and ' $b$ '. Each component of the total radiation stress tensor is composed of the superposition of the primary waves tensor components added to nonlinear interaction functions. The additional terms generate a non-uniform and transient stress field with a period related to the properties of the primary waves. Low frequency components are represented by terms which include the time averaged phase differences, $\overline{\cos \left(\phi_{a}-\phi_{b}\right)}$, while the high frequency terms are multiplied by $\overline{\cos \left(\phi_{a}+\phi_{b}\right)}$. These results significantly differ from those originally presented by Longuet-Higgins and Stewart (1964) for unimodal and unidirectional waves, and later expanded to oblique waves by Hsu et al. (2006) and Shi and Kirby (2008), or a simple linear superposition as proposed by Battjes (1972) for short-crested waves.

The expressions presented in Appendix 1 reduce to the usual form of the radiation stress components for monochromatic-monodirectional waves (e.g. DEAN; DALRYMPLE, 1991). To illustrate the physical interpretation of the equations for the mean water level and radiation stresses components for $\mathrm{Bi}-\mathrm{Bi}$ waves, some examples will be shown in the next sections.

\section{Methodology}

Conde et al. (2014) performed physical model tests with bichromatic-monodirectional waves in a wave flume at the National Laboratory for Civil Engineering (LNEC). The flume had a total length of $32.57 \mathrm{~m}$, the water depth was $0.95 \mathrm{~m}$ near the wave-maker, and then varied from $0.55 \mathrm{~m}$ to $0.10 \mathrm{~m}$ in a constant 1:22 slope, before reaching a constant depth region $(10 \mathrm{~cm})$ and the absorption system. The simulated bichromatic waves had $1.1 \mathrm{~s}$ and $1.5 \mathrm{~s}$, both being $0.08 \mathrm{~m}$ high. The instrumentation consisted of an eight-gauge movable structure $1.8 \mathrm{~m}$ long, with the sensors positioned $0.2 \mathrm{~m}$ apart. Measurements were taken on a $20 \mathrm{~m}$ stretch of the channel. An ADV probe took measurements at mid-depth, spaced by $1 \mathrm{~m}$ on a $17 \mathrm{~m}$ stretch. Using time, spectral and wavelet analysis, the authors studied nonlinear wave transformations on the slope and on the $10 \mathrm{~m}$ long subsequent horizontal bed. The spectral and wavelet analysis clearly identified the presence of the infragravity wave, with frequency equal to the difference of the two basic frequencies (4.125 s) and energy higher than that of the second harmonic of the primary waves. Further information about the experiments and data analysis can be found in Conde et al. (2013) and Conde, Lemos and Fortes (2014).

Ma et al. (2017) investigated in laboratory the interaction of monochromatic-bidirectional waves building an experimental set-up consisting of two crossing flumes inside a wave basin. The angle difference between both waves was fixed to $24^{\circ}$, and different wave frequencies and amplitudes were simulated. Capacitance wave probes and high-speed cameras were used to investigate the wave-wave interactions and showed that they are strongly dependent on wave amplitude and frequency.

A natural extension of Conde et al. (2014) and Ma et al. (2017) would be adding both, wave directionality and frequency, to the experiments and study the behavior of the infragravity wave with different combinations of angle difference between the primary waves. Using a computer program written in Python, a broad set of tests can be made to help better understand the nonlinear processes involved in 3D physical model tests to be carried out in a wave basin.

De Souza e Silva, Rosman and Neves (2017) compared the Bi-Bi's mean water level and radiation stresses to the results obtained by the traditional formulas for monochromatic-monodirectional waves (e.g. Dean; Dalrymple, 1991). A series of tests were simulated with monochromatic-bidirectional waves using the $\mathrm{Bi}$-Bi waves formulas and a $\Delta \theta$ ranging from $0^{\circ}$ to $360^{\circ}$. The results showed that for angle differences of $0^{\circ}$ and $180^{\circ}$, and an equal initial phase $\left(\varepsilon_{a}=\varepsilon_{b}\right)$, the calculated mean water level was identical to traditional formulas and that it varies through all possible angle combinations as a continuous and smooth curve. The maximum setup and setdown variations occurred for a steep stationary wave and for a progressive bichromatic-bidirectional wave with small angle differences. For the radiation stresses, the Mohr's circle was used, a well-known technique in Continuum Mechanics for representing stresses states. It was concluded that these second order terms significantly change the Mohr's circle's diameter and center, meaning that the nonlinearity should not be disregarded neither in numerical nor in physical models.

The focus here is on the transformations experienced by the infragravity wave and the stress tensor components on a 1:22 slope if the experiments of Conde et al. (2014) were to be made in a 3D wave basin. Bi-Bi waves were simulated using the same periods and height combinations tested by Conde: $1.1 \mathrm{~s}$ (wave ' $\mathrm{a}$ ') and $1.5 \mathrm{~s}$ (wave 'b'), and $0.08 \mathrm{~m}$ for each wave at the wave maker. Wave ' $\mathrm{b}$ ' had a constant direction of $0^{\circ}$ (normal to the wave maker), while the shorter wave was rotated by $1^{\circ}$ in each test until completing $360^{\circ}$.

The simulated 3D wave basin in Figure 4 is $30 \mathrm{~m}$ wide, $6.5 \mathrm{~m}$ long and has a 1:22 slope in the $\mathrm{x}$-axis. The water depth ranged from $0.55 \mathrm{~m}(\mathrm{x}=0 \mathrm{~m})$ to $0.26 \mathrm{~m}(\mathrm{x}=6.5 \mathrm{~m})$. The shallow limit was set by the Ursell criteria for second order Stokes theory, which prevented the slope to reach $0.10 \mathrm{~m}$ depth as in Conde's experiment. Three different positions at the center $\mathrm{x}$-axis of the basin $(y=0 \mathrm{~m})$ were chosen to illustrate some results: $\mathrm{x}_{1}=0 \mathrm{~m}$

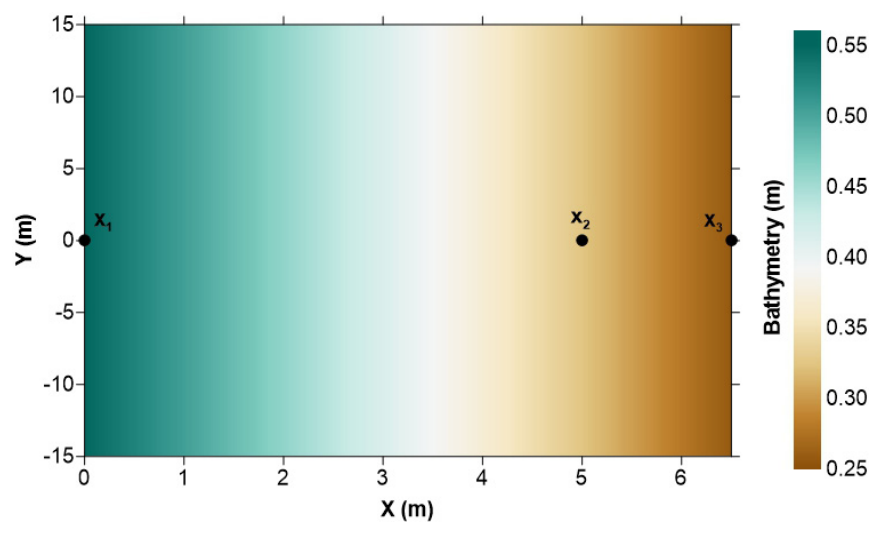

Figure 4. Bathymetry of the numerical 3D wave basin. Black circles show the three chosen points for more detailed analysis. Horizontal and vertical scales are distorted. 
$\left(\mathrm{h}_{1}=0.55 \mathrm{~m}\right) ; \mathrm{x}_{2}=5 \mathrm{~m}\left(\mathrm{~h}_{2}=0.33 \mathrm{~m}\right)$ and $\mathrm{x}_{3}=6.5 \mathrm{~m}\left(\mathrm{~h}_{3}=0.26 \mathrm{~m}\right)$. In all simulations, both waves propagated in intermediate water conditions.

\section{RESULTS AND DISCUSSION}

Results for the mean water level and the radiation stress components will be shown here. Unless otherwise stated, all graphs illustrate the results for position $\mathrm{x}_{1}$, where both waves have zero initial phase $\left(\varepsilon_{\mathrm{a}}=\varepsilon_{\mathrm{b}}=0\right)$. A detailed analysis about the effects of the phase difference can be seen in De Souza e Silva, Rosman and Neves (2017).

\section{Phase structure}

Consider two waves whose wave numbers are $\mathbf{k}_{\mathbf{a}}$ and $\mathbf{k}_{\mathbf{b}}$ as shown in Figure 5, where the wave 'a' may have any direction $\left(360^{\circ}\right)$ relative to wave ' $\mathrm{b}$ '. Both subtractive and additive interferences will have wave lengths given by the magnitude of the difference or addition of the primary wave number vectors; as long as the

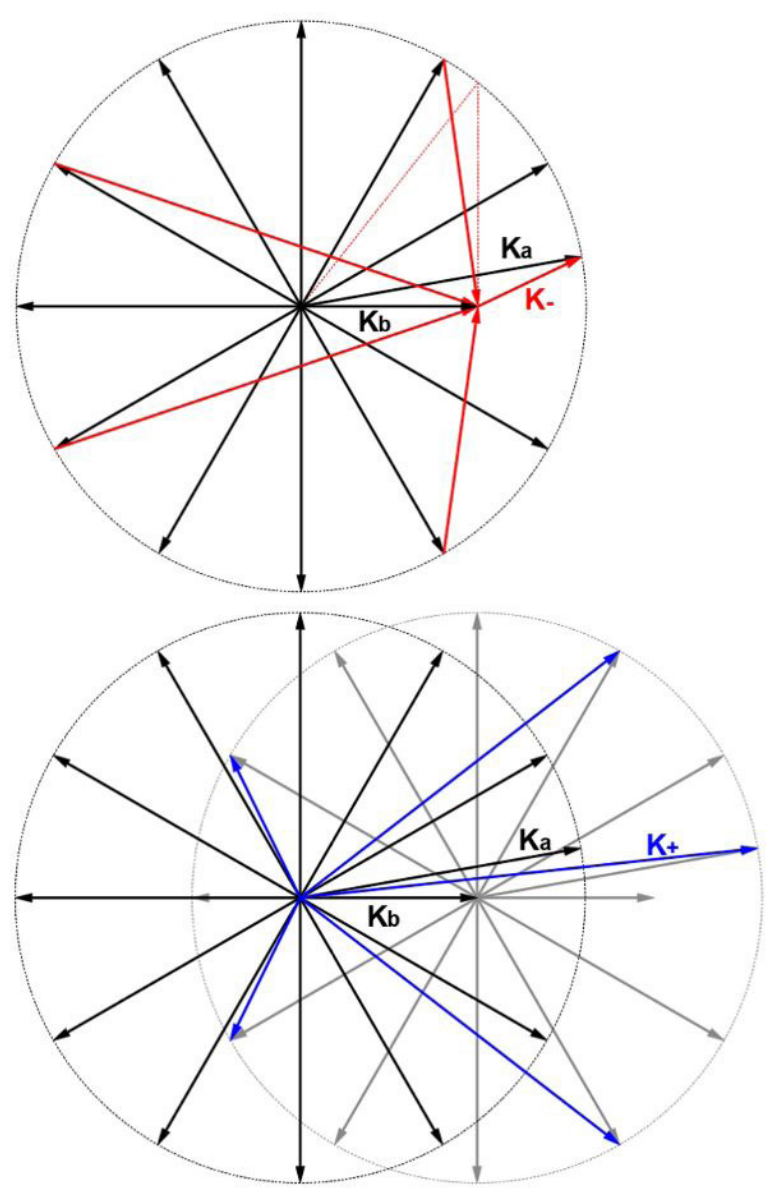

Figure 5. (a) Subtractive (red) and (b) additive (blue) wave numbers resulting from wave-wave interaction. primary periods are not equal, the interference will move in space and time as a bound wave, in the direction of the resulting wave number vector. The wave lengths of the interferences will be given as $2 \pi /\left|\mathbf{k}_{\mathrm{a}} \pm \mathbf{k}_{\mathrm{b}}\right|$, with period $\mathrm{T}_{\mathrm{a}} \mathrm{T}_{\mathrm{b}} /\left|\mathrm{T}_{\mathrm{a}} \pm \mathrm{T}_{\mathrm{b}}\right|$. The direction of propagation of the interference wave will be limited to an angle $\theta_{\lim }$ relative to the shorter wave 'a' as given by Equation (11).

$$
\theta_{\lim }=\sin ^{-1} \frac{\left|\mathbf{k}_{\mathbf{b}}\right|}{\left|\mathbf{k}_{\mathbf{a}}\right|}
$$

Depending on the angle between the primary waves, the interference wave length may be either longer or shorter than the primary waves. This is a remarkable result, different from what happens with wave groups formed by collinear waves, whose wave length is always longer than the wave length of the primary waves.

Experimental studies conducted by Conde et al. (2014) in LNEC's wave flume showed the presence of not only the first subtractive interference, but also the interference between higher harmonics. In a wave basin, one might expect that third or higher order interference may develop more easily. Table 1 summarizes the interference periods, both subtractive and additive, for the primary waves with $1.1 \mathrm{~s}$ and $1.5 \mathrm{~s}$.

\section{Mean water level}

Equation (6) allows computing the mean water level for any combination of angle and period of $\mathrm{Bi}-\mathrm{Bi}$ waves. Figure 6 shows continuous curves that describes the maximum and minimum mean water level height under all possible combinations of angle difference between $1.1 \mathrm{~s}$ and $1.5 \mathrm{~s}$ period waves along the slope. The setup and setdown are more significant at $0^{\circ}$ angle difference. Around $60^{\circ}$, the effects over the mean water level are minimum and when both waves tend to propagate with opposite directions, the influence of the nonlinear interactions grow.

Table 1. Interference matrix: subtractive period $(-)$ and additive period $(+)$.

\begin{tabular}{|c|c|c|c|c|}
\hline \multirow{2}{*}{\multicolumn{2}{|c|}{$\begin{array}{c}\text { Interference } \\
\text { Matrix }\end{array}$}} & \multirow{2}{*}{$\frac{1^{\text {st }} \text { Order }}{\sigma_{\mathrm{a}}}$} & \multirow{3}{*}{$\frac{\frac{2^{\text {nd }} \text { Order }}{2 \sigma_{\mathrm{a}}}}{2 \sigma_{\mathrm{a}} \pm \sigma_{\mathrm{b}}}$} & \multirow{3}{*}{$\frac{3^{\text {rd }} \text { Order }}{3 \sigma_{a}}$} \\
\hline & & & & \\
\hline $1^{\text {st }}$ Order & $\sigma_{\mathrm{b}}$ & $\sigma_{\mathrm{a}} \pm \sigma_{\mathrm{b}}$ & & \\
\hline $2^{\text {nd }}$ Order & $2 \sigma_{\mathrm{b}}$ & $\sigma_{\mathrm{a}} \pm 2 \sigma_{\mathrm{b}}$ & $2 \sigma_{\mathrm{a}} \pm 2 \sigma_{\mathrm{b}}$ & $3 \sigma_{\mathrm{a}} \pm 2 \sigma_{\mathrm{b}}$ \\
\hline $3^{\text {rd }}$ Order & $3 \sigma_{\mathrm{b}}$ & $\sigma_{\mathrm{a}} \pm 3 \sigma_{\mathrm{b}}$ & $2 \sigma_{\mathrm{a}} \pm 3 \sigma_{\mathrm{b}}$ & $3 \sigma_{\mathrm{a}} \pm 3 \sigma_{\mathrm{b}}$ \\
\hline \multirow{2}{*}{\multicolumn{2}{|c|}{$\begin{array}{l}\text { period (-) } \\
\text { (s) }\end{array}$}} & $T_{a}$ & $\mathbf{T}_{\mathrm{a}} / 2$ & $T_{a} / 3$ \\
\hline & & 1.10 & 0.55 & 0.37 \\
\hline $\mathbf{T}_{\mathrm{b}}$ & 1.50 & 4.125 & 0.868 & 0.485 \\
\hline $\mathrm{T}_{\mathrm{b}} / 2$ & 0.75 & 2.357 & 2.063 & 0.717 \\
\hline $\mathrm{T}_{\mathrm{b}} / 3$ & 0.50 & 0.917 & 5.500 & 1.375 \\
\hline \multirow{2}{*}{\multicolumn{2}{|c|}{$\begin{array}{l}\text { period }(+) \\
(s)\end{array}$}} & $\mathbf{T}_{\mathrm{a}}$ & $\mathrm{T}_{\mathrm{a}} / 2$ & $\mathrm{~T}_{\mathrm{a}} / 3$ \\
\hline & & 1.10 & 0.55 & 0.37 \\
\hline $\mathbf{T}_{\mathrm{b}}$ & 1.50 & 0.635 & 0.402 & 0.295 \\
\hline$T_{b} / 2$ & 0.75 & 0.446 & 0.317 & 0.246 \\
\hline$T_{b} / 3$ & 0.50 & 0.344 & 0.262 & 0.212 \\
\hline
\end{tabular}


Figure 7 shows the expected infragravity wave generated by the Bi-Bi waves inside the basin, for the case where wave ' $a$ ' has a $10^{\circ}$ angle and wave 'b' a $0^{\circ}$ angle in deep water condition. Refraction and shoaling effects are considered in the model. The angle difference at $\mathrm{x}_{1}, \mathrm{x}_{2}$ and $\mathrm{x}_{3}$ positions are $9.6^{\circ}, 8.5^{\circ}$ and $7.9^{\circ}$, respectively. Because of this decreasing angle difference and the increase in the steepness of the primary waves, the infragravity wave changes direction and increases its height as it propagates along the basin slope. The drawn arrows in the figure indicate the propagation direction of this long bound wave, which is a function of the primary wave numbers. At $\mathrm{x}_{1}, \mathrm{x}_{2}$ and $\mathrm{x}_{3}$, the direction of the infragravity wave is $24.5^{\circ}, 24.7^{\circ}$ and $24.0^{\circ}$, respectively.

It is important to keep in mind that Figure 7 shows an instant in time. When time is allowed to vary, the progressive characteristic of the infragravity wave becomes evident.

The curves in Figure 6 and the snapshot of the mean water level in Figure 7 are helpful to understand what happens to the infragravity wave as Bi-Bi waves approach the shore. As refraction and shoaling affect the incoming waves, they tend to propagate at smaller angles with respect to the isobaths in shallower water depth. The bound wave then, rapidly increases its height, while its direction changes according to the difference of the wave number

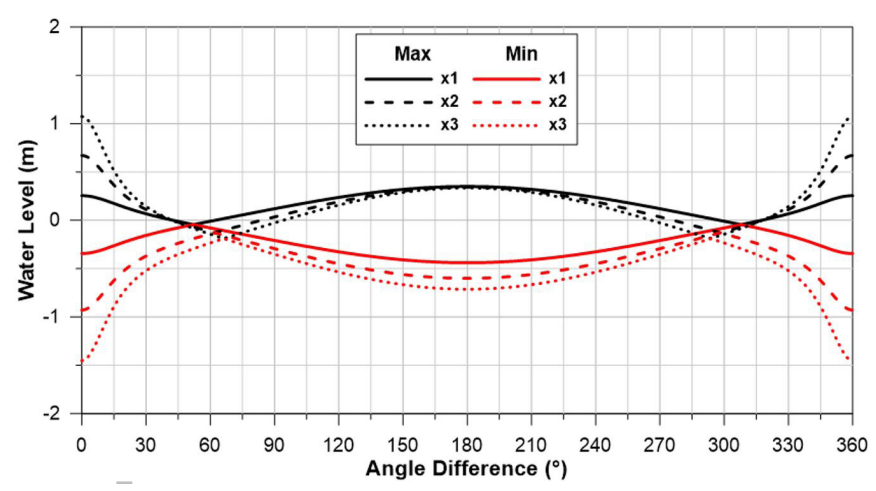

Figure 6. Setup or setdown of the mean water level with the propagation of $\mathrm{Bi}-\mathrm{Bi}$ waves $\left(\mathrm{T}_{\mathrm{a}}=1.1 \mathrm{~s}\right.$ and $\left.\mathrm{T}_{\mathrm{b}}=1.5 \mathrm{~s}\right)$.

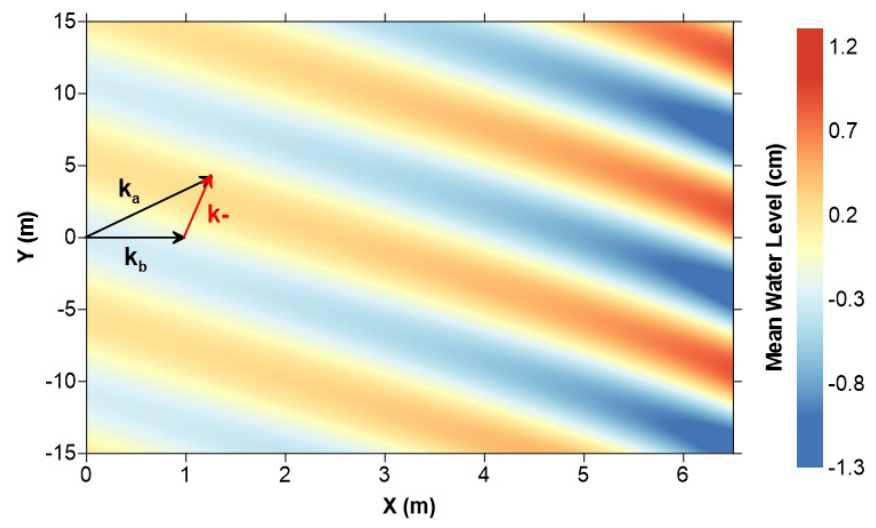

Figure 7. Infragravity wave oscillation inside the $3 \mathrm{D}$ numerical basin. Arrows are just an illustration of the wave number vector of the primary waves (black) and infragravity wave (red). vectors of the primary waves. However, even a slight difference in angle of propagation between the primary waves, will cause the infragravity wave to propagate in a direction that is neither one of the primary waves.

\section{Radiation stresses}

Closely analyzing the radiation stress equations shown in Appendix 1, one can see the importance of the angle difference between the primary waves. Figure 8 shows the Mohr's circles of the stress tensor resulting from different combinations of directions for the $1.1 \mathrm{~s}$ and $1.5 \mathrm{~s}$ period waves at the bottom of the slope $\left(\mathrm{h}_{1}=0.55 \mathrm{~m}\right)$. The normal and shear stress components are higher when both waves propagate in the same direction. As the angle difference increases, the diameter of the Mohr's circle decreases down to a minimum around $120^{\circ}$, and then it gradually increases again until both waves propagate in opposite directions. It is interesting to notice that this pattern is different from the one shown in De Souza e Silva, Rosman and Neves (2017) for monochromatic-bidirectional waves, where the Mohr's circle had a maximum diameter at $0^{\circ}$ angle difference (progressive wave) and a minimum at $180^{\circ}$ (standing wave). As a matter of fact, the radiation stress field of $\mathrm{Bi}-\mathrm{Bi}$ waves strongly depends on the angle and the period combination of the primary waves.

Figure 9 shows the Mohr's circle at positions $\mathrm{x}_{1}, \mathrm{x}_{2}$ and $\mathrm{x}_{3}$ in the simulated wave basin. As the angle difference between the primary waves decreases and their steepness increase, the center of the circle moves away from the $\mathrm{y}$-axis (because $\left(\mathrm{S}_{\mathrm{xx}}+\mathrm{S}_{\mathrm{Yy}}\right) / 2$ grows at shallow water), while increasing its diameter (because $S_{x \mathrm{v}}$ also grows).

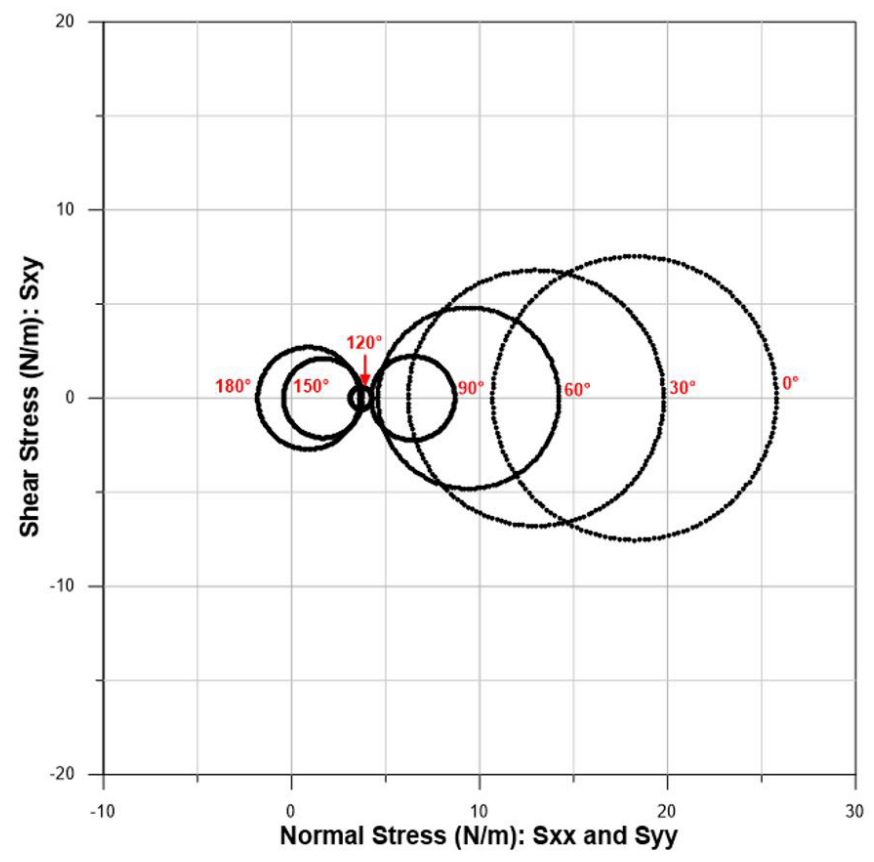

Figure 8. The Mohr's circles for different angle differences between waves 'a' and 'b'. 


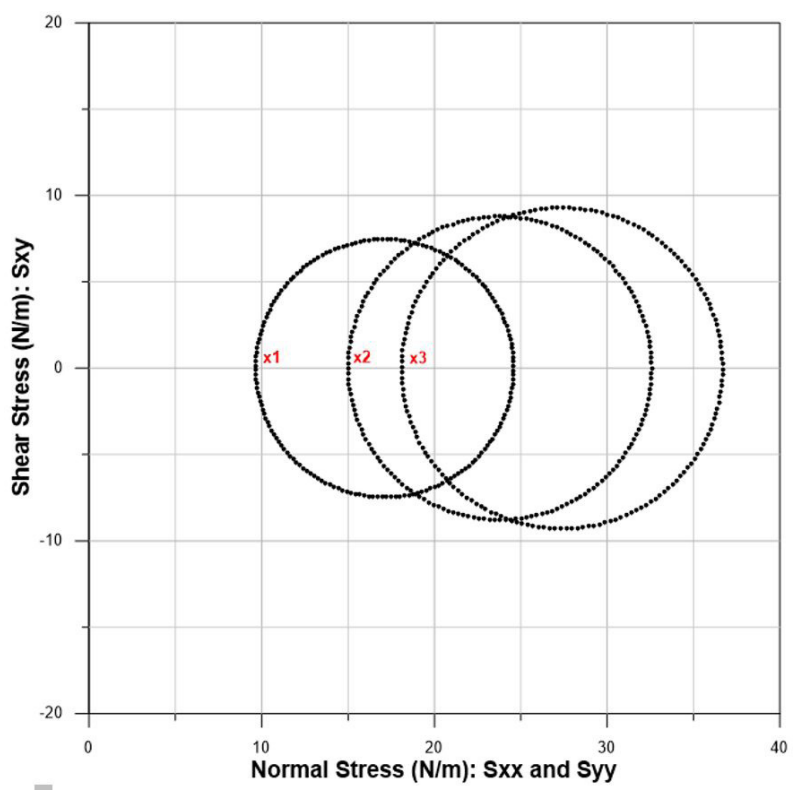

Figure 9. The Mohr's circle at the three positions in the 3D basin: $\mathrm{x}_{1}$ is the deepest and $\mathrm{x}_{3}$ the shallowest.

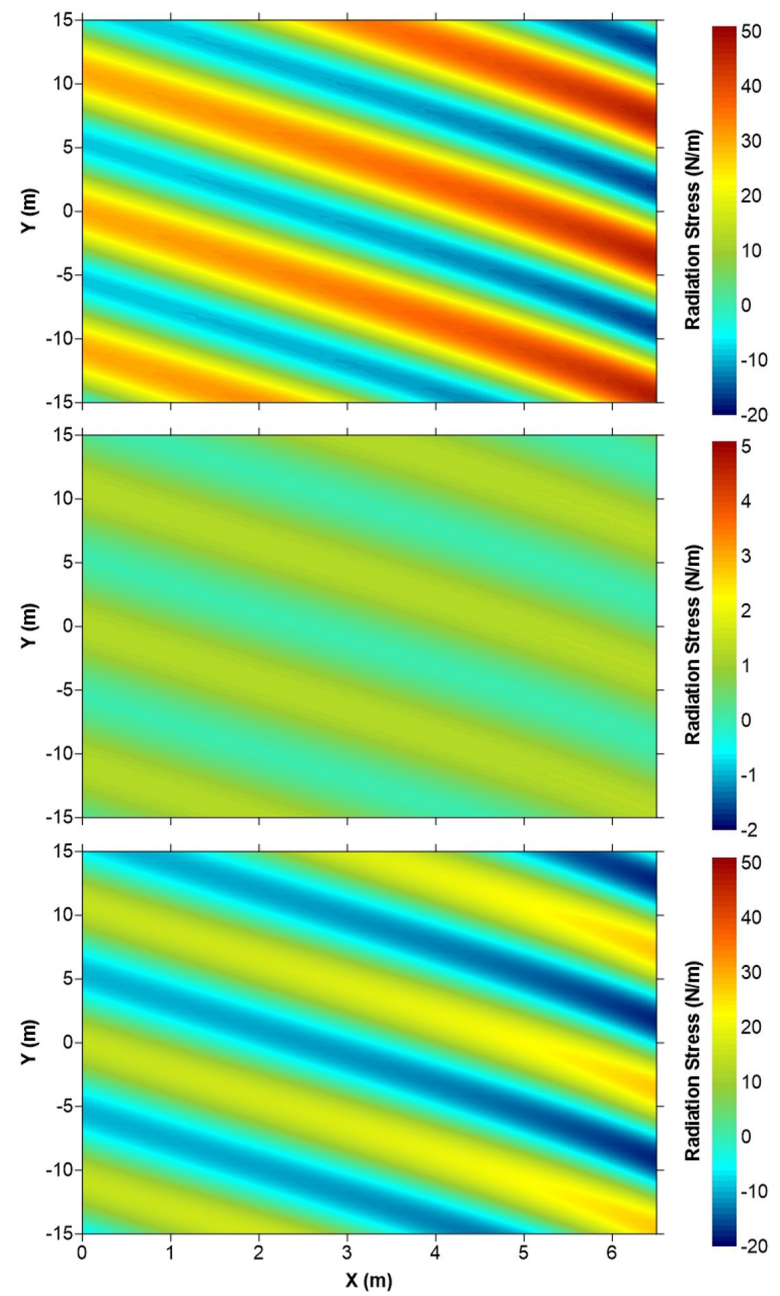

Figure 10. Radiation stress field of the three stress components: $\mathrm{S}_{\mathrm{xx}}, \mathrm{S}_{\mathrm{xy}}$ and $\mathrm{S}_{\mathrm{yy}}$, respectively.
Figure 10 shows the radiation stress field for each of the three components of the stress tensor $\left(\mathrm{S}_{\mathrm{xx}}, \mathrm{S}_{\mathrm{xy}}\right.$ and $\left.\mathrm{S}_{\mathrm{yy}}\right)$, for the case where wave ' $a$ ' $\left(\mathrm{T}_{\mathrm{a}}=1.1 \mathrm{~s}\right)$ has a $10^{\circ}$ angle and wave 'b' $\left(\mathrm{T}_{\mathrm{b}}=1.5 \mathrm{~s}\right)$ a $0^{\circ}$ angle in deep water conditions. The patterns of each component are similar to the infragravity wave, as the intensities become more pronounced as the waves propagate along the slope and the crests are curved due to refraction of the primary waves.

At this point, it is interesting to investigate the nonlinear terms of the equations in Appendix 1 of the radiation stress field. Figure 11 shows the exact same condition shown in Figure 10 but disregarding the nonlinear terms. It is seen that in the normal components $\left(\mathrm{S}_{\mathrm{xx}}\right.$ and $\left.\mathrm{S}_{\mathrm{yy}}\right)$ only variations in the cross-shore direction appear, while the shear stress component $\left(\mathrm{S}_{\mathrm{xy}}\right)$ is constant all over the basin. This result significantly differs from the one illustrated in Figure 10, where all three stress components oscillates in the cross and longshore directions. This result suggests the importance of including nonlinear terms in numerical models when two or more waves approach the shore simultaneously.

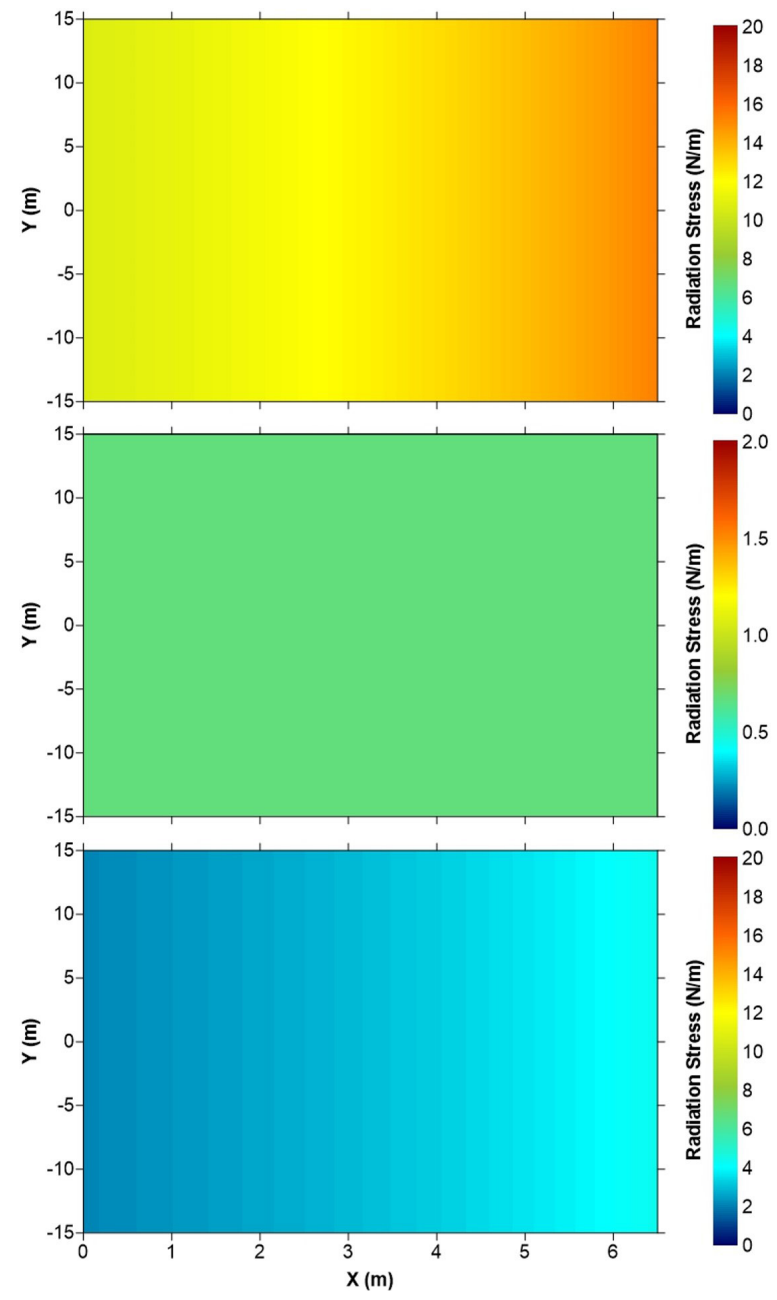

Figure 11. Radiation stress field, disregarding the nonlinear terms: $\mathrm{S}_{\mathrm{xx}}, \mathrm{S}_{\mathrm{xy}}$ and $\mathrm{S}_{\mathrm{yy}}$, respectively. 


\section{CONCLUSION}

Bimodal spectra may be thought of as group of waves with two primary frequencies but collinear (same direction). However, it is important to keep in mind that these spectra could be the superposition of two different wave systems with also different directions, which contain multiple wave-wave interaction components. Conde et al. (2014) investigated the nonlinear bichromatic-monodirectional wave interactions in a wave flume with a 1:22 slope. Spectral and wavelet analysis have clearly identified the frequency corresponding to the main infragravity wave but have also shown other interference patterns.

The present work investigated the effect of including wave directionality to the bichromatic pattern. A computer program written in Python was used in this investigation, which included the $\mathrm{Bi}-\mathrm{Bi}$ second order equations for calculating the mean water level and radiation stresses. The simulated waves were based in the physical model presented in Conde et al. (2014), with $1.1 \mathrm{~s}$ and $1.5 \mathrm{~s}$, but now could have any combination of directions. The numerical 3D basin simulated a wave basin $6.5 \mathrm{~m}$ long, $30 \mathrm{~m}$ wide, with depth ranging from $0.55 \mathrm{~m}$ to $0.26 \mathrm{~m}$ on a $1: 22$ slope.

The effects of the Bi-Bi waves on setup and setdown of the mean water level and on the radiation stress tensor were compared to the monochromatic formulations presented in the literature. It was seen that, for waves with $1.1 \mathrm{~s}$ and $1.5 \mathrm{~s}$ periods, the setup and setdown are more pronounced close to $0^{\circ}$ and $180^{\circ}$ difference of angle between the waves and that around $60^{\circ}$ the effects of the nonlinearities over the mean water level are minimum. It was also seen that near the shore, the infragravity wave behaves as a progressive wave, travelling in the longshore direction. This is an extension of the findings made by Dalrymple (1975), which showed a standing wave being generated by monochromatic-bidirectional wave system.

Concerning the radiation stress tensor, it was shown that the infragravity wave generated by $\mathrm{Bi}-\mathrm{Bi}$ waves creates an oscillating radiation stress field variable in the longshore and cross-shore directions, a phenomenon which does not occur with monochromatic waves. Even the shear stress component $\left(\mathrm{S}_{\mathrm{Xy}}\right)$, which is considered as a constant for monochromatic wave in the offshore zone, undergoes significant spatial variations for $\mathrm{Bi}-\mathrm{Bi}$ waves. These results are significantly different from what is expected by the equations developed for monochromatic oblique waves by Shi and Kirby (2008), in which case there would be no net forces outside the surf zone to drive nearshore circulations. For $\mathrm{Bi}-\mathrm{Bi}$ waves, however, there are important cross-shore and longshore variations, both in space and time of the radiation stresses in all three components which should be taken into account in numerical models. Yet, physical experiments in a wave basin are still needed to validate these theoretical results.

Regarding coastal morphology, this spatial variation of second order terms may be able to mobilize bars in the surf zone and to generate spatially varying longshore currents. As the mean sea level propagates along the shore as a long-period wave, another consequence of $\mathrm{Bi}-\mathrm{Bi}$ waves might be the formation and longshore displacement of rip currents, sources of risk to beach goers and an important nearshore water renewal agent. Regarding coastal works, significant damage may result from the long period oscillatory excitation, such as resonance in structures (e.g. piers, ocean outfalls), as well as harbor resonance.

\section{ACKNOWLEDGEMENTS}

This study was financed in part by the Coordenação de Aperfeiçoamento de Pessoal de Nível Superior - Brasil (CAPES) Finance Code 001. The authors also acknowledge and are thankful for the support of the Ocean Engineering Program of the Federal University of Rio de Janeiro.

\section{REFERENCES}

AAGAARD, T.; GREENWOOD, B. Infragravity wave contribution to surf zone sediment transport - The role of advection. Marine Geology, v. 251, n. 1-2, p. 1-14, 2008. http://dx.doi.org/10.1016/j. margeo.2008.01.017.

ARDHUIN, F.; GUALTIERI, L.; STUTZMANN, E. How ocean waves rock the Earth: Two mechanisms explain microseisms with periods 3 to 300 s. Geophysical Research Letters, v. 42, n. 3, p. 765-772, 2015. http://dx.doi.org/10.1002/2014GL062782.

BATTJES, J. A. Set-up due to irregular waves. Coastal Engineering Proceedings, n. 13, p. 1993-2004, jul. 1972.

BERTIN, X.; DE BAKKER, A.; VAN DONGEREN, A.; COCO, G.; ANDRÉ, G.; ARDHUIN, F.; BONNETON, P.; BOUCHETTE, F.; CASTELLE, B.; CRAWFORD, W. C.; DAVIDSON, M.; DEEN, M.; DODET, G.; GUÉRIN, T.; INCH, K.; LECKLER, F.; MCCALL, R.; MULLER, H.; OLABARRIETA, M.; ROELVINK, D.; RUESSINK, G.; SOUS, D.; STUTZMANN, É.; TISSIER, M. Infragravity waves: from driving mechanisms to impacts. Earth-Science Reviews, v. 177, p. 774-799, 2018. http:// dx.doi.org/10.1016/j.earscirev.2018.01.002.

CHERITON, O. M.; STORLAZZI, C. D.; ROSENBERGER, K. J. Observations of wave transformation over a fringing coral reef and the importance of low-frequency waves and offshore water levels to runup, overwash, and coastal flooding. Journal of Geophysical Research. Oceans, v. 121, n. 5, p. 3121-3140, 2016. http:// dx.doi.org/10.1002/2015JC011231.

CONDE, J. M. P.; FORTES, C. J.; DIDIER, E.; LEMOS, R. Physical modelling of bichromatic wave propagation and wave breaking in a wave flume. In: INTERNATIONAL SHORT CONFERENCE OF APPLIED COASTAL RESEARCH, 6., 2013, Lisbon, Portugal. Proceedings... Lisbon, 2013, p. 2-2.

CONDE, J. M. P.; LEMOS, R.; FORTES, C. J. Comparison between time, spectral and wavelet analysis on wave breaking and propagation. In: 3RD IAHR EUROPE CONGRESS, 3., 2014, Porto, Portugal. Proceedings... Lisbon, 2014, p. 10-10.

CONDE, J. M. P.; NEVES, C. F.; FORTES, C. J. E. M.; LEMOS, R. Experimental wave breaking velocity characterization for monochromatic, 
bichromatic and irregular waves. In: INTERNATIONAL CONFERENCE ON THE APPLICATION OF PHYSICAL MODELLING TO PORT AND COASTAL PROTECTION - COASTLAB, 5., 2014, Varna, Bulgaria. Proceedings... Varna: Black Sea - Danube Coastal Research Association, 2014, p. 87-96.

DALRYMPLE, R. A. A mechanism for rip current generation on an open coast. Journal of Geophysical Research, v. 80, n. 24, p. 3485-3487, 1975. http://dx.doi.org/10.1029/JC080i024p03485.

DALRYMPLE, R. A.; LANAN, G. A. Beach cusps formed by intersecting waves. Geological Society of America Bulletin, v. 87, n. 1, p. 57-60, 1976. http://dx.doi.org/10.1130/00167606(1976)87<57:BCFBIW>2.0.CO;2.

DALRYMPLE, R. A.; MACMAHAN, J. H.; RENIERS, A. J. H. M.; NELKO, V. Rip currents. Annual Review of Fluid Mechanics, v. 43, n. 1, p. 551-581, 2011. http:/ / dx.doi.org/10.1146/annurevfluid-122109-160733.

DE SOUZA E SILVA, M. G.; ROSMAN, P. C. C.; NEVES, C. F. Nonlinear second order effects of bichromatic-bidirectional waves. In: INTERNATIONAL SHORT CONFERENCE ON APPLIED COASTAL RESEARCH, 8., 2017, Santander, Spain. Proceedings... Santander, 2017, p. 12-12.

DEAN, R. G.; DALRYMPLE, R. A. Water wave mechanics for engineers and scientists. World Scientific Publishing Co. Pte. Ltd., 1991. http://dx.doi.org/10.1142/1232.

FOWLER, R. E; DALRYMPLE, R. A. Wave group forced nearshore circulation. Coastal Engineering Proceedings, n. 22, p. 729-742, may. 1990. https://doi.org/10.9753/icce.v22.\%25p.

GENG, X.; BOUFADEL, M. C. Numerical study of solute transport in shallow beach aquifers subjected to waves and tides. Journal of Geophysical Research Oceans, v. 120, n. 2, p. 1409-1428, 2015. http://dx.doi.org/10.1002/2014JC010539.

HSU, T. W.; HSU, J. R. C.; WENG, W. K.; WANG, S. K.; OU, S. H. Wave setup and setdown generated by obliquely incident waves. Coastal Engineering, v. 53, n. 10, p. 865-877, 2006. http:/ / dx.doi.org/10.1016/j.coastaleng.2006.05.002.

HSU, T. W.; LAN, Y. J. Reply to "Discussion of wave setup and setdown generated by obliquely incident waves" by F. Shi and J.T. Kirby. Coastal Engineering, v. 56, n. 3, p. 382-383, 2009. http:/ / dx.doi.org/10.1016/j.coastaleng.2008.12.003.

INMAN, D. L.; TAIT, R. J.; NORDSTROM, C. E. Mixing in the surf zone. Journal of Geophysical Research, v. 76, n. 15, p. 3493-3514, 1971. http://dx.doi.org/10.1029/JC076i015p03493.

JANSSEN, T. T. Long waves induced by short-wave groups over a sloping bottom. Journal of Geophysical Research, v. 108, n. C8, p. 3252, 2003. http://dx.doi.org/10.1029/2002JC001515.
LI, L.; BARRY, D. A. Wave-induced beach groundwater flow. Advances in Water Resources, v. 23, n. 4, p. 325-337, 2000. http:/ / dx.doi.org/10.1016/S0309-1708(99)00032-9.

LONGUET-HIGGINS, M. S. A Theory of the Origin of Microseisms. Philosophical Transactions of the Royal Society A: Mathematical, Physical and Engineering Sciences, v. 243, n. 857, p. 1-35, 1950. http://dx.doi.org/10.1098/rsta.1950.0012.

LONGUET-HIGGINS, M. S. Wave set-up, percolation and undertow in the surf zone. Proceedings of the Royal Society A: Mathematical, Physical and Engineering Sciences, v. 390, n. 1799, p. 283-291, dec. 1983.

LONGUET-HIGGINS, M. S.; STEWART, R. W. Radiation stresses in water waves; a physical discussion, with applications. Deep Sea Research and Oceanographic Abstracts, v. 11, n. 4, p. 529562, 1964. http://dx.doi.org/10.1016/0011-7471(64)90001-4.

MA, Y.; LIU, D.; LIU, W.; DONG, G.; PERLIN, M. Interactions of two identical wave trains with a relative separation angle of 24. Journal of Ocean University of China, v. 16, n. 4, p. 683-688, 2017. http://dx.doi.org/10.1007/s11802-017-3412-7.

MELO, E.; ALVES, J. H. G. M.; JORDEN, V.; ZAGO, F; DIAS, W. S. S. Instrumental confirmation of the arrival of north atlantic swell to the ceará coast. In: INTERNATIONAL CONFERENCE ON COASTAL AND PORT ENGINEERING IN DEVELOPING COUNTRIES - COPEDEC, 4., 1995, Rio de Janeiro, Brasil. Proceedings... Rio de Janeiro: FURG, 1995, p. 1984-1996.

MUNK, W. H. Surf beats. American Geophysical Union, v. 30, n. 6, p. 849-854, 1949. http://dx.doi.org/10.1029/TR030i006p00849.

PARENTE, C. E.; NOGUEIRA, I. C. M.; MARTINS, R. P.; RIBEIRO, E. O. Climatologia de ondas. In: MARTINS, R. P.; GROSSMANN-MATHESON, G.S. (Eds.). Meteorologia e oceanografia. Rio de Janeiro: Elsevier, 2015. p. 55-96. (Habitats, v. 2). http://dx.doi.org/10.1016/B978-85-352-6208-7.50009-X.

RAPIZO, H.; BABANIN, A. V.; SCHULZ, E.; HEMER, M. A.; DURRANT, T. H. Observation of wind-waves from a moored buoy in the Southern Ocean. Ocean Dynamics, v. 65, n. 9-10, p. 1275-1288, 2015. http://dx.doi.org/10.1007/s10236-015-0873-3.

SHARMA, J. N.; DEAN, R. G. Second-order directional seas and associated wave forces. Society of Petroleum Engineers Journal, v. 21, n. 01, p. 129-140, 1981. http://dx.doi.org/10.2118/8584-PA.

SHI, F.; KIRBY, J. T. Discussion of "Wave setup and setdown generated by obliquely incident waves" by T.-W. Hsu et al., Coastal Engineering, 53, 865-877, 2006. Coastal Engineering, v. 55, n. 12, p. 1247-1249, 2008. http://dx.doi.org/10.1016/j. coastaleng.2008.08.001. 
TUCKER, M. J. Surf beats: sea waves of 1 to 5 min. period. Proceedings - Royal Society. Mathematical, Physical and Engineering Sciences, v. 202, n. 1071, p. 565-573, 1950.

XIE, M. X. Three-dimensional numerical modelling of the wave-induced rip currents under irregular bathymetry. Journal of Hydrodynamics, v. 24, n. 6, p. 864-872, 2012.

YOUNG, A. P.; ADAMS, P. N.; O'REILLY, W. C.; FLICK, R. E.; GUZA, R. T. Coastal cliff ground motions from local ocean swell and infragravity waves in southern California. Journal of Geophysical Research, v. 116, n. C9, p. C09007, 2011. http://dx.doi. org/10.1029/2011JC007175.

ZHANG, J.; CHEN, L. General third-order solutions for irregular waves in deep water. Journal of Engineering Mechanics, v. 125, n.
7, p. 768-779, 1999. http://dx.doi.org/10.1061/(ASCE)07339399(1999)125:7(768).

\section{Authors contribution}

Mario Grüne de Souza e Silva: Main writer of this article and responsible for the data analysis.

Paulo Cesar Colonna Rosman: Reviewed the article and presented suggestions.

Claudio Freitas Neves: Wrote part of the article and supervised the data analysis procedure. 
Appendix 1. Radiation Stress Equations

$$
\begin{aligned}
& S_{x x}=E_{a}\left[n_{a}\left(\cos ^{2} \theta_{a}+1\right)-\frac{1}{2}\right]+E_{b}\left[n_{b}\left(\cos ^{2} \theta_{b}+1\right)-\frac{1}{2}\right]- \\
& \frac{\rho h H_{a} H_{b}}{8}\left\{\left[\sigma_{a}^{2}+\sigma_{b}^{2}-\frac{\sigma_{a} \sigma_{b} \cos (\Delta \theta)}{\tanh \left(k_{a} h\right) \tanh \left(k_{b} h\right)}+\sigma_{a} \sigma_{b}\right] \overline{\cos \left(\phi_{a}+\phi_{b}\right)}+\left[\sigma_{a}^{2}+\sigma_{b}^{2}-\frac{\sigma_{a} \sigma_{b} \cos (\Delta \theta)}{\tanh \left(k_{a} h\right) \tanh \left(k_{b} h\right)}-\sigma_{a} \sigma_{b}\right] \overline{\cos \left(\phi_{a}-\phi_{b}\right)}\right\}- \\
& \rho h\left[\left(\sigma_{a}+\sigma_{b}\right) \cosh \left(\left|\mathbf{k}_{\mathbf{a}}+\mathbf{k}_{\mathbf{b}}\right| h\right) A_{a b}^{+} \overline{\cos \left(\phi_{a}+\phi_{b}\right)}+\left(\sigma_{a}-\sigma_{b}\right) \cosh \left(\left|\mathbf{k}_{\mathbf{a}}-\mathbf{k}_{\mathbf{b}}\right| h\right) A_{a b}^{-} \overline{\cos \left(\phi_{a}-\phi_{b}\right)}\right]+ \\
& \frac{\rho H_{a} H_{b} \sigma_{a} \sigma_{b}}{16 \sinh \left(k_{a} h\right) \sinh \left(k_{b} h\right)}\left\{\begin{array}{l}
\left\{\frac{2 g \sinh \left(k_{a} h\right) \sinh \left(k_{b} h\right)}{\sigma_{a} \sigma_{b}}+\frac{\sinh \left[\left|\mathbf{k}_{\mathbf{b}}+\mathbf{k}_{\mathbf{a}}\right| h\right]}{\left|\mathbf{k}_{\mathbf{b}}+\mathbf{k}_{\mathbf{a}}\right|}\left[\cos \left(\theta_{a}+\theta_{b}\right)+1\right]+\frac{\sinh \left[\mathbf{k}_{\mathbf{b}}-\mathbf{k}_{\mathbf{a}} \mid h\right]}{\left|\mathbf{k}_{\mathbf{b}}-\mathbf{k}_{\mathbf{a}}\right|}\left[\cos \left(\theta_{a}+\theta_{b}\right)-1\right]\right\} \overline{\cos \left(\phi_{a}+\phi_{b}\right)}+ \\
+\left\{\frac{2 g \sinh \left(k_{a} h\right) \sinh \left(k_{b} h\right)}{\sigma_{a} \sigma_{b}}+\frac{\sinh \left[\mathbf{k}_{\mathbf{b}}+\mathbf{k}_{\mathbf{a}} \mid h\right]}{\left|\mathbf{k}_{\mathbf{b}}+\mathbf{k}_{\mathbf{a}}\right|}\left[\cos \left(\theta_{a}+\theta_{b}\right)-1\right]+\frac{\sinh \left[\mathbf{k}_{\mathbf{b}}-\mathbf{k}_{\mathbf{a}} \mid h\right]}{\left|\mathbf{k}_{\mathbf{b}}-\mathbf{k}_{\mathbf{a}}\right|}\left[\cos \left(\theta_{a}+\theta_{b}\right)+1\right]\right\} \overline{\cos \left(\phi_{a}-\phi_{b}\right)}
\end{array}\right\} \\
& S_{y y}=E_{a}\left[n_{a}\left(\sin ^{2} \theta_{a}+1\right)-\frac{1}{2}\right]+E_{b}\left[n_{b}\left(\sin ^{2} \theta_{b}+1\right)-\frac{1}{2}\right]- \\
& \frac{\rho h H_{a} H_{b}}{8}\left\{\left[\sigma_{a}^{2}+\sigma_{b}^{2}-\frac{\sigma_{a} \sigma_{b} \cos (\Delta \theta)}{\tanh \left(k_{a} h\right) \tanh \left(k_{b} h\right)}+\sigma_{a} \sigma_{b}\right] \overline{\cos \left(\phi_{a}+\phi_{b}\right)}+\left[\sigma_{a}^{2}+\sigma_{b}^{2}-\frac{\sigma_{a} \sigma_{b} \cos (\Delta \theta)}{\tanh \left(k_{a} h\right) \tanh \left(k_{b} h\right)}-\sigma_{a} \sigma_{b}\right] \overline{\cos \left(\phi_{a}-\phi_{b}\right)}\right\}- \\
& \rho h\left[\left(\sigma_{a}+\sigma_{b}\right) \cosh \left(\left|\mathbf{k}_{\mathbf{a}}+\mathbf{k}_{\mathbf{b}}\right| h\right) A_{a b}^{+} \overline{\cos \left(\phi_{a}+\phi_{b}\right)}+\left(\sigma_{a}-\sigma_{b}\right) \cosh \left(\left|\mathbf{k}_{\mathbf{a}}-\mathbf{k}_{\mathbf{b}}\right| h\right) A_{a b}^{-} \overline{\cos \left(\phi_{a}-\phi_{b}\right)}\right]- \\
& \frac{\rho H_{a} H_{b} \sigma_{a} \sigma_{b}}{16 \sinh \left(k_{a} h\right) \sinh \left(k_{b} h\right)} \times\left\{\begin{array}{l}
\left\{-\frac{2 g \sinh \left(k_{a} h\right) \sinh \left(k_{b} h\right)}{\sigma_{a} \sigma_{b}}+\frac{\sinh \left[\left|\mathbf{k}_{\mathbf{b}}+\mathbf{k}_{\mathbf{a}}\right| h\right]}{\left|\mathbf{k}_{\mathbf{b}}+\mathbf{k}_{\mathbf{a}}\right|}\left[\cos \left(\theta_{a}+\theta_{b}\right)-1\right]+\frac{\sinh \left[\left|\mathbf{k}_{\mathbf{b}}-\mathbf{k}_{\mathbf{a}}\right| h\right]}{\left|\mathbf{k}_{\mathbf{b}}-\mathbf{k}_{\mathbf{a}}\right|}\left[\cos \left(\theta_{a}+\theta_{b}\right)+1\right]\right\} \overline{\cos \left(\phi_{a}+\phi_{b}\right)}+ \\
\left\{-\frac{2 g \sinh \left(k_{a} h\right) \sinh \left(k_{b} h\right)}{\sigma_{a} \sigma_{b}}+\frac{\sinh \left[\mathbf{k}_{\mathbf{b}}+\mathbf{k}_{\mathbf{a}} \mid h\right]}{\left|\mathbf{k}_{\mathbf{b}}+\mathbf{k}_{\mathbf{a}}\right|}\left[\cos \left(\theta_{a}+\theta_{b}\right)+1\right]+\frac{\sinh \left[\mathbf{k}_{\mathbf{b}}-\mathbf{k}_{\mathbf{a}} \mid h\right]}{\left|\mathbf{k}_{\mathbf{b}}-\mathbf{k}_{\mathbf{a}}\right|}\left[\cos \left(\theta_{a}+\theta_{b}\right)-1\right]\right\} \overline{\cos \left(\phi_{a}-\phi_{b}\right)}
\end{array}\right\} \\
& S_{x y}=\frac{E_{a}}{2} n_{a} \sin 2 \theta_{a}+\frac{E_{b}}{2} n_{b} \sin 2 \theta_{b}+ \\
& \frac{\rho H_{a} H_{b} \sigma_{a} \sigma_{b} \sin \left(\theta_{a}+\theta_{b}\right)}{16 \sinh \left(k_{a} h\right) \sinh \left(k_{b} h\right)}\left\{\frac{\sinh \left[\left|\mathbf{k}_{\mathbf{b}}+\mathbf{k}_{\mathbf{a}}\right| h\right]}{\left|\mathbf{k}_{\mathbf{b}}+\mathbf{k}_{\mathbf{a}}\right|}+\frac{\sinh \left[\left|\mathbf{k}_{\mathbf{b}}-\mathbf{k}_{\mathbf{a}}\right| h\right]}{\left|\mathbf{k}_{\mathbf{b}}-\mathbf{k}_{\mathbf{a}}\right|}\right\}\left[\overline{\cos \left(\phi_{a}+\phi_{b}\right)}+\overline{\cos \left(\phi_{a}-\phi_{b}\right)}\right]
\end{aligned}
$$

